\title{
EVOLUÇÃO DE UMA ÁREA DEGRADADA - ESTUDO DE CASO DA MATA DA BIOLOGIA
}

Larissa Carvalho Santos - lari.carvalhoufv@gmail.com

Universidade Federal de Viçosa - UFV

Lívia Dal Sasso de Souza - liviadsasso@gmail.com

Universidade Federal de Viçosa - UFV 


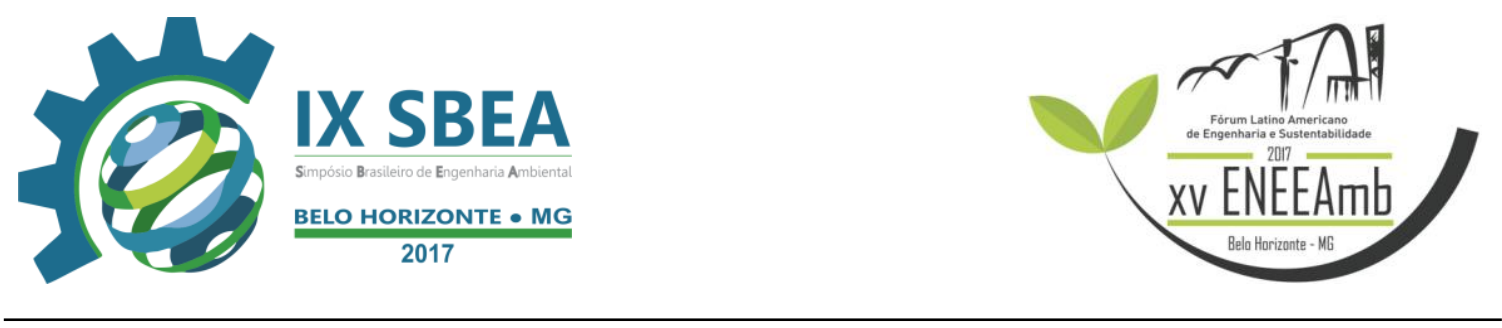

\section{RESUMO}

As florestas em regeneração têm ocupado uma área cada vez maior do estado de Minas Gerais, em virtude das alterações que as florestas primárias sofreram. Objetivou-se realizar um estudo de caso acerca das condições fitossociológicas e edáficas da Mata da Biologia da Universidade Federal de Viçosa, para estabelecer uma correlação entre o passado da área e seu uso atual. Atualmente a mata se encontra como uma comunidade secundária, parcialmente protegida de cortes e extração de madeira. Apesar da recuperação ambiental desenvolvida, a fragmentação florestal gerou ilhas de vegetação, comprometendo a composição, a estrutura e a dinâmica da vegetação. Por se tratar de um fragmento da Mata Atlântica, apresenta potencial para realização de pesquisas, atividades educacionais e de extensão. Apesar de não existir um gestor responsável pelo seu monitoramento, inúmeros estudos são realizados na localidade, incluindo teses e dissertações sobre a fauna, flora, solo, e educação ambiental. A escassez dos recursos voltados para a manutenção da Mata evidencia a necessidade de um plano de recuperação da área, bem como um projeto de supervisão do local.

Palavras-chave: Educação ambiental, mata atlântica, recuperação de área degradada.

\section{INTRODUÇÃO/OBJETIVO}

As Florestas Estacionais Semideciduais existentes na Zona da Mata mineira são as principais representantes dos remanescentes de Mata Atlântica dessa região. Devido, principalmente, aos ciclos de café e à pecuária, essas florestas passaram por perturbações que levaram à fragmentação da vegetação (BRAGA et al., 2011).

As florestas em regeneração vêm ocupando uma área cada vez maior do estado de Minas Gerais, em virtude das alterações que as florestas primárias sofreram, especialmente nas últimas décadas, pela a extração de madeira ou atividades agropastoris. Esse cenário culminou na formação de um mosaico que engloba o remanescente de floresta primária cercado por florestas secundárias de regeneração, de várias idades, além das pastagens e áreas cultivadas (RIBAS et al., 2003).

A degradação ambiental causada pelas atividades antrópicas é a principal responsável pela mudança no perfil fitossociológico das florestas. Entende-se por degradação quaisquer alterações sutis ou graduais que reduzem a integridade e a saúde 


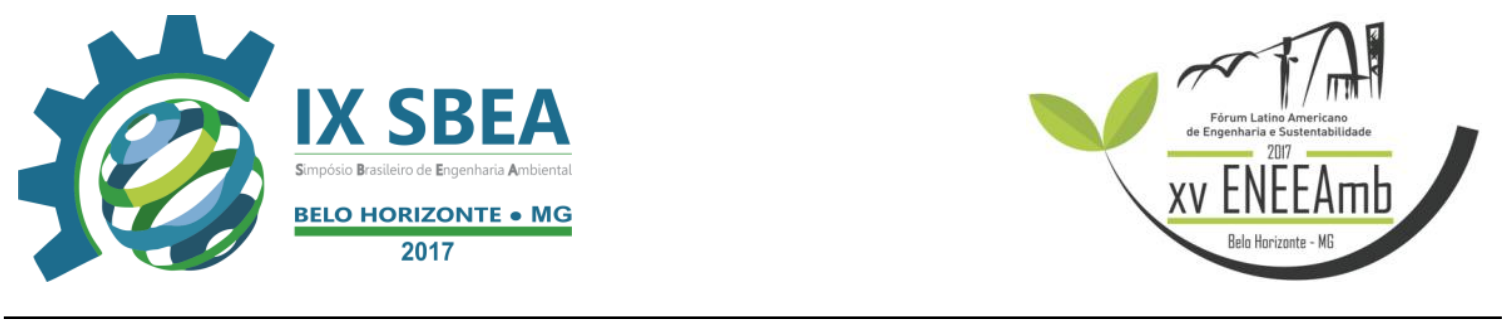

de um ecossistema (SER, 2004). Além da destruição dos recursos naturais, a degradação de um ecossistema tem um impacto negativo direto sobre o bem estar humano e social.

Para recuperar, reabilitar, restaurar ou proteger uma área degradada, faz-se necessário um levantamento das condições atuais do local e de seu entorno. Para o entendimento da dinâmica da área, também é relevante o levantamento histórico, a fím de se conhecer as alterações sofridas ao longo dos anos. Estas informações serão essenciais nos projetos ambientais desenvolvidos, por exemplo, em um Projeto de Recuperação de Áreas Degradas (PRADs).

Objetivou-se neste estudo de caso realizar um levantamento histórico das condições fitossociológicas e edáficas da Mata da Biologia da Universidade Federal de Viçosa, a fim de se estabelecer uma correlação entre o passado da área e seu uso atual.

\section{CARACTERIZAÇÃO DA ÁREA}

O local de estudo, pertencente a um fragmento do Jardim Botânico da UFV conhecido como Mata da Biologia, constitui uma área de aproximadamente 75 hectares, situado no campus da Universidade Federal de Viçosa, no município de Viçosa, Minas Gerais, Brasil, nas coordenadas geográficas $20^{\circ} 45^{\prime} 66^{\prime \prime} \mathrm{S}$ e $42^{\circ} 51^{\prime} 67^{\prime \prime W}$. O clima local, de acordo com a classificação de Köppen, é do tipo Cwa, mesotérmico, com inverno frio e seco (temperaturas inferiores a $18^{\circ} \mathrm{C}$ ) e verão quente e chuvoso (temperaturas superiores a $22^{\circ} \mathrm{C}$ ). A temperatura média anual da região varia entre 14,6 e $21,8{ }^{\circ} \mathrm{C}$ e o índice pluviométrico anual é de cerca de $1200 \mathrm{~mm}$, concentrado de novembro a março. Na Figura 1 pode-se observar uma vista superior da área. 


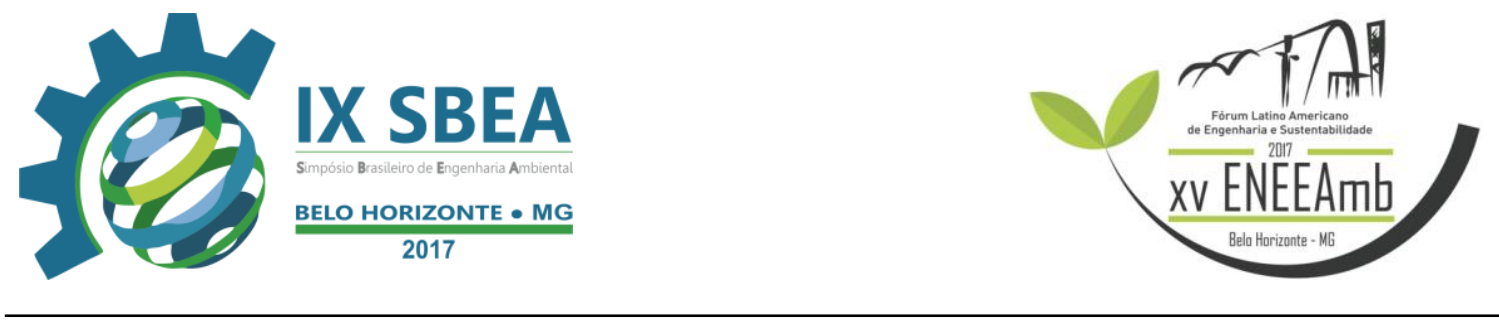

Figura 1 - Vista superior da Mata da Biologia

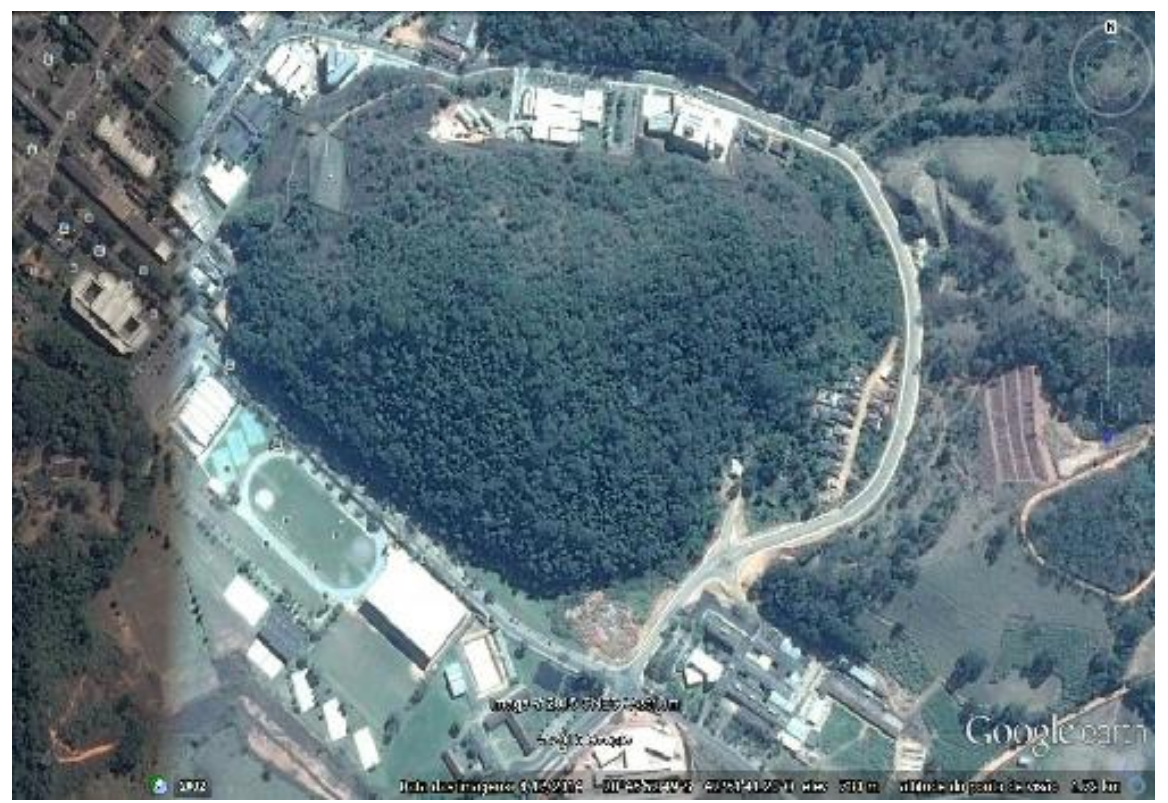

(Google Earth, 2017)

\section{HISTÓRICO DO USO E COUPAÇÃO DO SOLO}

No século XX, após o declínio da exploração de ouro em Minas Gerais, a Zona

da Mata especializou-se em agricultura e pecuária, que se caracterizavam principalmente pela monocultura predatória, pautada no desmatamento para o estabelecimento de novos plantios (PANIAGO, 1983). Golfari (1975) cita que as características do solo (latossolo vermelho-amarelo distrófico) e do relevo (mares de morros) acabaram por tornar as lavouras cafeeiras improdutivas, o que levou ao replantio das culturas com plantas de nova precessão ou, até mesmo, o abandono dos cultivos. Algumas dessas áreas foram ainda utilizadas para a pecuária em regime extensivo, o que dificultou ainda mais a regeneração natural das florestas (PANIAGO, 1893).

Em 1926, findada a exploração da área para práticas econômicas, e com a fundação da Escola Superior de Agricultura e Veterinária (ESAV), atual Universidade Federal de Viçosa, o cultivo foi abandonado e o local passou a integrar o campus da universidade, encontrando-se em processo de regeneração natural até os dias atuais, sob proteção permanente (PAULA et al., 2002). A antiga ESAV, na década de 20, é retratada na Figura 2. 


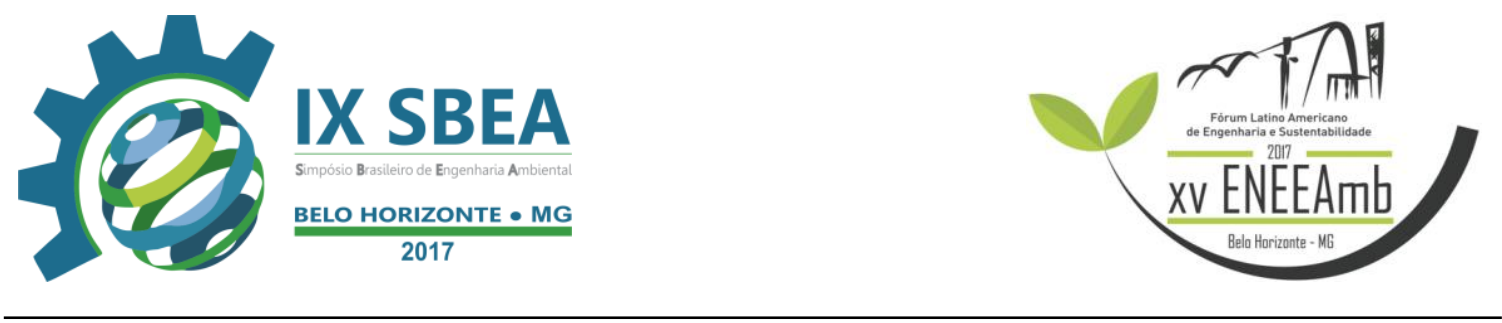

Figura 2 - ESAV, década de 20

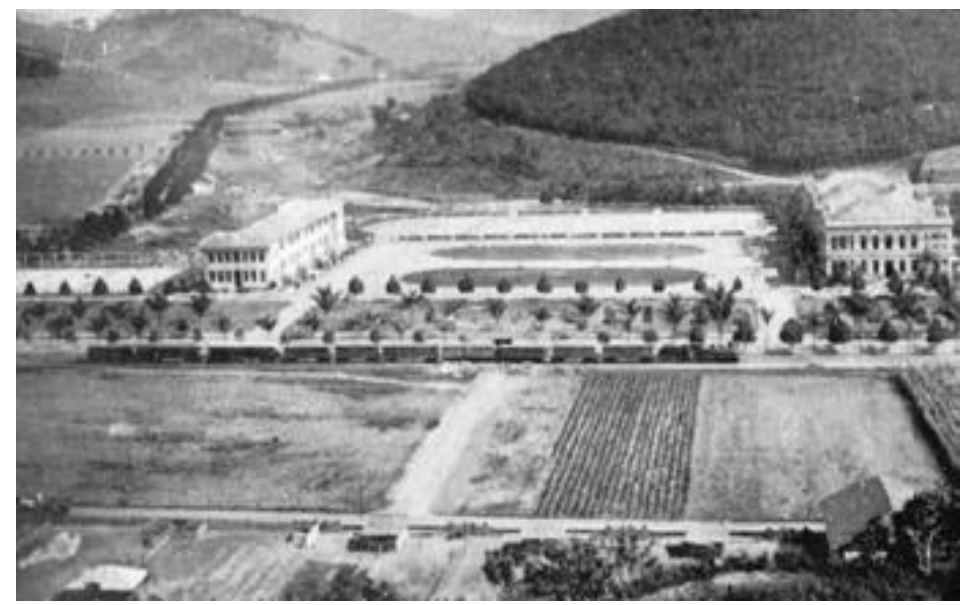

(Museu Histórico da UFV, 2017)

\section{RECUPERAÇÃO AMBIENTAL DA ÁREA E SITUAÇÃO ATUAL}

Durante o reflorestamento, uma das primeiras espécies utilizadas foi a araucária (Araucaria angustifolia). Nas etapas posteriores de regeneração outras espécies, como o angico-branco (Anadenanthera colubrina), a gameleira (Ficus insipida), a embaúba (Cecropia pachystachya) e o tamboril (Enterolobium contortisiliquum) cresceram na área (VIANA, 2011). Segundo Paula et al. (2002), o atual estágio sucessional do fragmento tem favorecido o estabelecimento de espécies tardias, em detrimento das iniciais (pioneiras e secundárias iniciais), denotando uma evolução sucessional no intervalo entre dois levantamentos considerados em sua análise, o que é esperado em fragmentos eficientemente preservados.

Atualmente a mata se encontra como uma comunidade secundária, parcialmente protegida de cortes e extração de madeira. Apesar da recuperação ambiental desenvolvida na área, a fragmentação florestal gerou "ilhas de vegetação" de diferentes tamanhos, formas e graus de isolamento, comprometendo a composição, a estrutura e a dinâmica da vegetação, sendo a perda da biodiversidade o principal impacto ambiental desse processo (VIANA, 1990).

Nesse contexto, as áreas da reserva mais próximas ao exterior tendem a ser mais iluminadas, tornando o ambiente mais quente e seco. A resposta das espécies presentes nessa região varia conforme suas próprias particularidades. Algumas não se adequam à baixa umidade, podendo sofrer prejuízos pelo efeito de borda, ocorrendo, em 


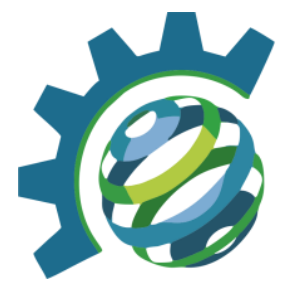

situações extremas, seu desaparecimento na localidade, comprometendo o equilíbrio da flora. Somando a esse quadro, as atividades antrópicas próximas reforçam a erosão, reduzindo a fauna do local e, consequentemente, diminuindo ou até impossibilitando a polinização e dispersão de frutos e sementes. As Figuras 3 e 4 ilustram o efeito de borda causado por uma rodovia e por construções localizadas nas adjacências do fragmento.

Figura 3 - Rodovia margeando a Mata da Biologia

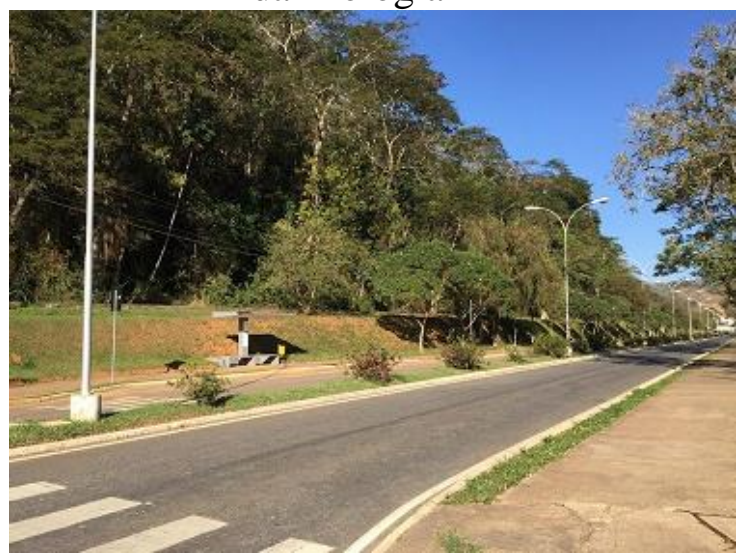

(Os autores, 2017)
Figura 4 - Erosão na mata observada próximo à construção no campus

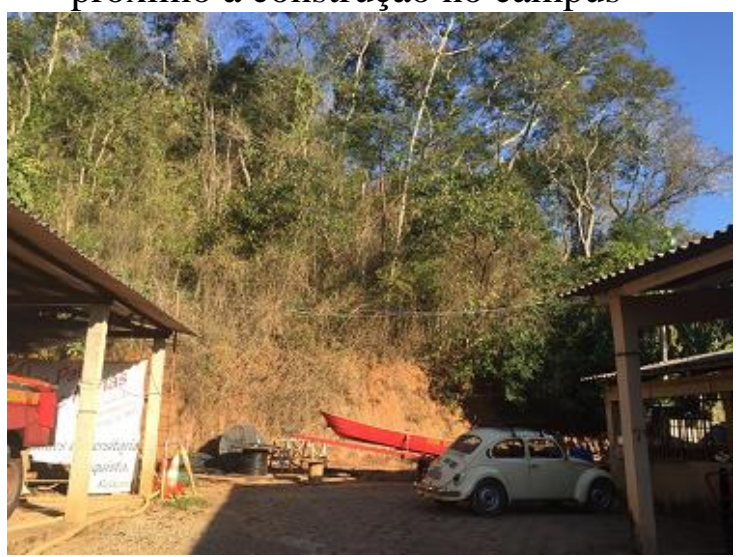

(Os autores, 2017)

Pontos de erosão também foram observados no interior da mata, possivelmente herança das práticas de monocultura desenvolvidas na área anteriormente.

Por se tratar de um fragmento da Mata Atlântica, o local apresenta potencial para realização de pesquisas, atividades educacionais e de extensão. Apesar de não existir um gestor responsável pelo seu monitoramento, inúmeros estudos são realizados na localidade, incluindo teses e dissertações sobre a fauna, flora, solo, e educação ambiental. Dentre as diversas atividades desenvolvidas, destaca-se o Projeto Sauá, gerido por um grupo de graduandos em biologia da UFV. Os "Trilheiros do Sauá", como se autodenominam, criaram uma trilha ecológica, identificada com placas interativas, informando os visitantes e possibilitando o contato com o meio natural.

Dias et al. (1986) citado por Silva (1996), afirma que a interpretação da natureza no contexto de uma trilha ecológica é uma atividade educativa que tem como objetivo a revelação de significados, relações ou fenômenos naturais por intermédio de 
experiências práticas e meios interpretativos, ao invés da simples comunicação de fatos e datas. É também uma forma de dividir experiências que levam as pessoas a apreciar, entender e cooperar com a conservação de um recurso natural. Na Figura 5 é registrada a primeira placa da trilha ecológica da Mata da Biologia.

Figura 5 - Primeira placa da trilha interpretativa da Trilha do Sauá

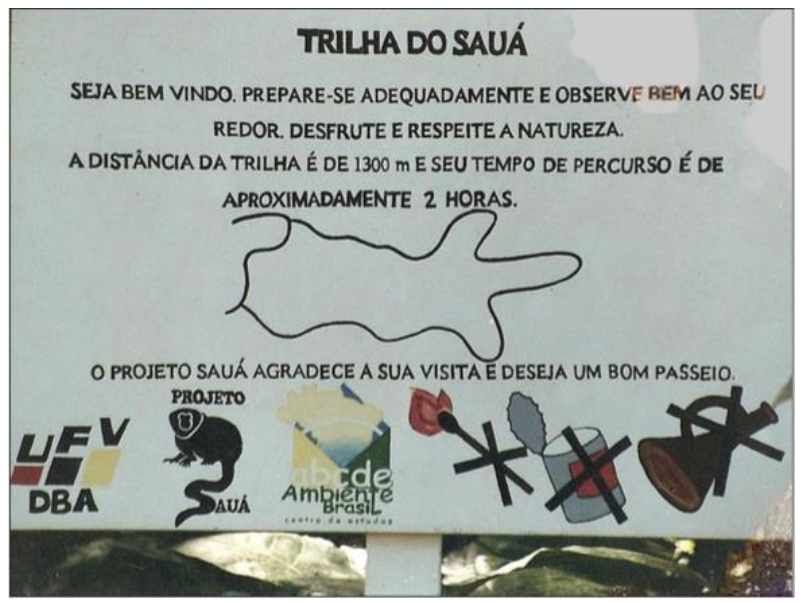

(Os autores, 2017)

\section{CONCLUSÕES/RECOMENDAÇÕES}

A Mata da Biologia é considerada um fragmento da mata Atlântica, portanto, de máxima importância na conservação da biodiversidade. Sua utilização pública deixa claro o papel social da área para a comunidade, sendo ela tanto fonte de informações para pesquisas nas mais diferentes vertentes, quanto prestadora de serviços para a comunidade considerando os projetos de educação ambiental desenvolvidos.

Entretanto, as constantes atividades realizadas em seu entorno, de forma inadequada, colocam em risco sua integridade, podendo causar danos irreparáveis ao seu tênue equilíbrio e, até mesmo, impossibilitar futuras utilizações da área.

Diante da escassez dos recursos voltados para a manutenção da Mata, fica evidente a necessidade de novas ações de recuperação da área, bem como um projeto de supervisão do local. A utilização de métodos de manutenção de biodiversidade, como corredores ecológicos, viveiros de mudas e métodos de preservação, são importantes para preservar a Mata contra maiores perturbações ecológicas. 


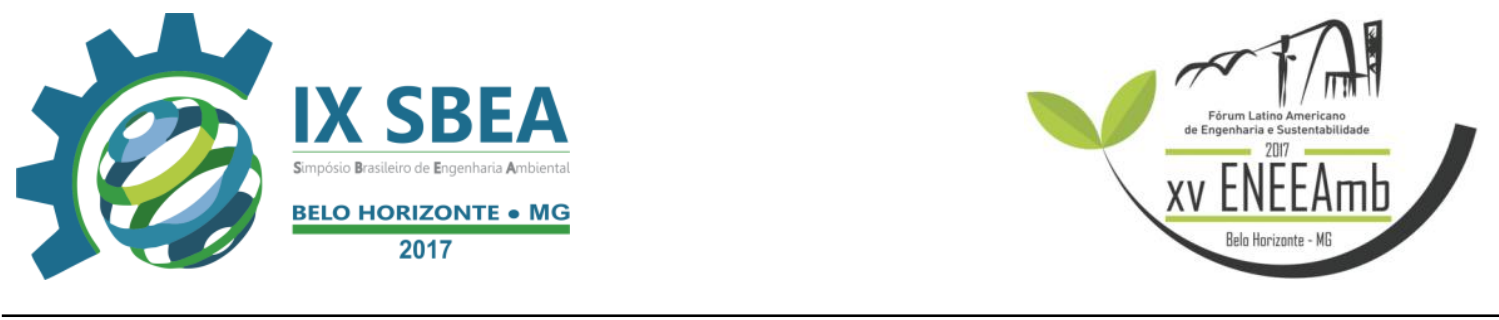

Considerando as atividades de forma geral, pode-se afirmar que uma nova gestão deveria considerar a manutenção adequada da área de convívio; um registro preciso das estações de pesquisa; a supervisão constante das trilhas, a fim de garantir a segurança dos frequentadores; uma fiscalização adequada, impedindo que visitantes tenham uma conduta inapropriada na propriedade; e desenvolvimento de projetos que visem amenizar os efeitos de borda.

\section{REFERÊNCIAS BIBLIOGRÁFICAS}

BRAGA, A. J. T.; BORGES, E. E. L.; MARTINS, S. V. Florística e estrutura da comunidade arbórea de uma Floresta Estacional Semidecidual Secundária em Viçosa, MG. Revista Árvore. v. 35, n.3, p.493-503, 2011.

GOLFARI, L. Zoneamento ecológico do Estado de Minas para reflorestamento. Belo Horizonte: PRODEPEF/PNUD/FAO/IBDF/Bra-45, 1975. 65 p. (Série técnica, 3).

PANIAGO, M. C. T. Evolução histórica e tendências de mudanças sócio-culturais na comunidade de Viçosa - MG. Viçosa-MG, UFV, 1983. 407 p. Dissertação (Mestrado em Economia Rural) - Universidade Federal de Viçosa, 1983.

MILAGRES, A. P. Avaliação de uma trilha interpretativa como instrumento de educação ambiental usando sauá (Callicebus personatus nigrifrons) como espéciesímbolo para um programa de conservação no município de Viçosa, MG, 2000.

PAULA, A. et al. Alterações florísticas ocorridas num período de quatorze anos na vegetação arbórea de uma floresta estacional semidecidual em Viçosa - MG. Revista Árvore, v. 26, n. 6, p. 743-749, 2002.

Redação ambientebrasil, Corredor Biológico e Efeito de Borda. Disponível em: $<$ http://ambientes.ambientebrasil.com.br/unidades_de_conservacao/artigos_ucs/corredor biologico_e_efeito_de_borda.html> Acesso em 16 de setembro de 2016.

RIBAS, R. F.; MEIRA NETO, J. A. A.; SILVA, A. F.; SOUZA, A. L. Composição florística de dois trechos em diferentes etapas serais de uma Floresta Estacional Semidecidual em Viçosa, MG. Revista Árvore. v. 27, n.6, p.821-830, 2003.

SER - SOCIETY FOR ECOLOGICAL RESTORATION INTERNATIONAL, Grupo de Trabalho sobre Ciência e Política. Princípios da SER Internacional sobre Restauração Ecológica. Tradução de Griffith, J.J. et al. Tucson, 2004.

VIANA, I. B. ; CASTELO BRANCO, A.L ; PINTO, K. S. ; SALGADO, L.B.A ; Hélio Paulo Pereira Filho . UTILIZAÇÃO DE ÁREAS VERDES COMO RECURSO DIDÁTICO PARA O ENSINO DE CIÊNCIAS., Londrina, 2011. 


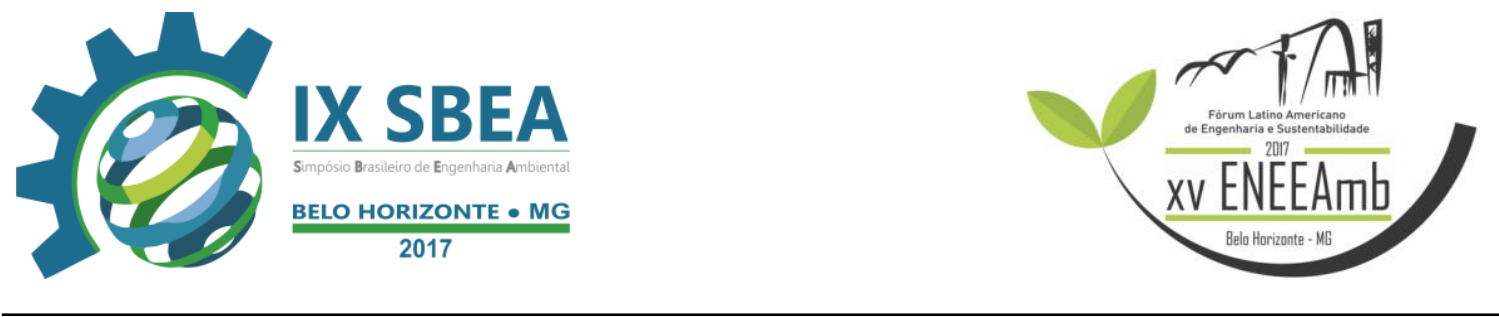

VIANA, V. M. Biologia e manejo de fragmentos de florestas naturais. 1990, Anais, São Paulo. SOCIEDADE BRASILEIRA DE SILVICULTURA, 1990. p. 113-118 